\title{
Selection for Female Fertility Using Censored Fertility Traits and Investigation of the Relationship with Milk Production
}

\author{
O. González-Recio, ${ }^{\star 1}$ R. Alenda,* Y. M. Chang,† K. A. Weigel,† and D. Gianola† \\ *Departamento de Producción Animal, Escuela Técnica Superior de Ingenieros Agrónomos-Universidad Politécnica de Madrid, \\ Ciudad Universitaria s/n, 28040 Madrid, Spain \\ †Department of Dairy Science, University of Wisconsin, Madison 53706
}

\section{ABSTRACT}

Bivariate models (censored linear-linear and censored threshold-linear) were used to estimate genetic parameters for production and fertility traits in the Spanish Holstein population. Records on 71,217 lactations from 41,515 cows were used: 30 and $36 \%$ of lactations were censored for days open (DO) and number of inseminations to conception (INS), respectively. Heritability estimates for production traits (milk, fat, protein) ranged between 0.18 and 0.25 . Heritability of days to first service (DFS) and DO was 0.05; heritability of INS on the liability scale was 0.04 . Genetic correlations between fertility traits were $0.41,0.71$, and 0.87 for DFS-INS, DO-INS, and DO-DFS, respectively. Days open had a larger genetic correlation (ranging from 0.63 to 0.76 ) with production traits than did DFS (0.47 to 0.59 ) or INS ( 0.16 to 0.23$)$. Greater antagonism between production and DO may be due to voluntary management decisions for high-yielding cows, resulting in longer lactation lengths. Inseminations to conception appeared to be less correlated with milk production than were the other 2 female fertility traits. Including INS in a total merit index would be expected to increase genetic gain in terms of profit, but profit would decrease if either DO or DO and DFS were included in the index. Thus, INS is the trait to be preferred when selecting for female fertility. The genetic correlation between actual milk yield and 305-d standardized milk yield was 0.96 in the present study, suggesting that some reranking of sires could occur. Because the target of attaining a 12mo calving interval, as implied by a $305-d$ standardized lactation length, is changing in the dairy industry, routine genetic evaluation of actual total lactation milk yield should be considered.

Key words: fertility, bivariate censored threshold-linear model, production

Received January 18, 2006.

Accepted June 29, 2006.

${ }^{1}$ Corresponding author: oscar.grecio@upm.es

\section{INTRODUCTION}

Improved reproduction makes cows more functional, reduces breeding and veterinary costs, and avoids involuntary disposal (Boichard, 1990; Stott et al., 1999; Vargas et al., 2002). In recent years, improving reproductive functionality has been one of the most important goals in dairy cattle breeding. However, the emphasis placed on milk production in selection indices makes simultaneous improvement of female fertility rather difficult. Antagonism between production and reproduction has been studied widely (Thaller, 1997; Veerkamp et al., 2001; Brotherstone et al., 2002). Highyielding cows tend to be less fertile, and this extends the length of the dry period and the calving interval, as well as the rate of involuntary disposal. Less fertile cows have decreased longevity, and their average total lifetime production can be up to $10,000 \mathrm{~kg}$ lower than that of cows with adequate fertility (González-Recio et al., 2004). Hence, a balance between production and functionality must be pursued, and proper economic weights must be applied to every trait.

Typically, yield traits have been standardized to 305 d. This adjustment made sense historically, when one calving per year was desired. However, standardization to $305 \mathrm{~d}$ may have several drawbacks at present. Degradation of fertility has led to cows that seldom have a 365 -d calving interval. Furthermore, high production in Holstein populations makes it possible to increase the DIM by lengthening the voluntary waiting period if the lactation is persistent enough. Lactation length was found to increase by $30 \mathrm{~d}$ in a similar population from 1990 to 2001 (González-Recio et al., 2004). This could lead to increased income from the sale of milk and could more quickly dilute rearing costs if the number of lactations remained constant. Furthermore, selection bias due to milk production could be partially accounted for by including yield in the multiple-trait analysis (Wall et al., 2003).

Days open (DO) is a widely used fertility trait, and it is the one recommended in populations that lack a detailed reproductive recording scheme (González-Recio and Alenda, 2005). González-Recio et al. (2004) esti- 
mated that the economic weight for the number of inseminations to conception (INS) was $24 \%$ of that for protein yield, and that this trait probably reflects actual genetic variation in female fertility more closely than does DO. Furthermore, days to first service (DFS) is an indicator of the postpartum return to reproductive function when heat synchronization is not practiced, as is the case in the Spanish dairy population. Therefore, these 3 fertility traits are of primary importance when selecting for female fertility.

Theoretically, it is necessary to estimate (co)variances among all traits to weight traits properly in a selection index. However, statistical analysis of fertility traits poses some difficulties because of censoring when the date of pregnancy or of successful insemination is unknown. Furthermore, the categorical nature of INS must be considered. Recent studies describe methodologies that can accommodate censored records for univariate analysis of DO (González-Recio et al., 2006) and INS (González-Recio et al., 2005). Previous studies showed that bivariate threshold-linear models could be more accurate than univariate models for genetic analysis of threshold traits (Varona et al., 2001). Also, bivariate censored threshold-linear models could be more suitable for analyzing the relationship between INS and other traits, such as milk yield.

The objective of this research was to study the relationships among fertility and actual and 305-d standardized milk yields while accommodating censored records for fertility. In addition, the expected genetic gains for milk yield and fertility were calculated, maximizing profit in herds with different selection indices.

\section{MATERIALS AND METHODS}

\section{Data}

Data were provided by the regional Holstein Associations from the Basque and Navarra Autonomous Regions of Spain. Milk yield and reproductive data from 1994 through 2004 were used in the analyses. Records from embryo transfers were omitted, and cows were required to have a minimum of 100 DIM before culling and at least $1,000 \mathrm{~kg}$ of total lactation milk yield to be included in the analysis. In addition, the calving interval had to range between 300 and $600 \mathrm{~d}$, and records were omitted if the DFS was unknown, less than $25 \mathrm{~d}$, or greater than $160 \mathrm{~d}$. Cows with first calvings before 18 mo or after 40 mo of age were excluded. At least 5 uncensored records were required per herd and per sire, and herds with an average INS of less than 1.5 were removed. Fertility records were considered as censored if no subsequent calving was reported, or if the outcome of a successful insemination was unknown. The last known insemination number and its date were consid- ered as the censoring points for INS and DO, respectively. In addition, if pregnancy was not achieved after the fourth insemination, INS was considered as censored at that point and included in a fifth category that represented more than 4 inseminations. Therefore, INS could take 5 values $(1,2,3,4$, or $>4)$. An indicator variable tagged each cow as being either pregnant or censored. Production traits were never censored, because only complete lactations were included in the analysis. For convenience, censoring for INS and DO were assumed to be independent and noninformative; however, the probability of censoring is arguably higher in less fertile cows. Uncensored DO have a skewed distribution (González-Recio et al., 2006), but the records were not transformed to ease interpretation. The edited data set contained 71,217 lactation records from 41,515 cows, and the pedigree file contained 85,974 animals.

\section{Bivariate Models}

Bayesian bivariate linear-linear and linear-threshold models allowing for censoring were fitted to analyze the following traits: 305-d adjusted milk yield (MY305), total milk yield (MY), fat and protein per lactation $(\mathrm{kg})$, DFS, and DO as linear traits, and INS as a threshold character. Data on all individuals are $(\mathbf{y}, \delta)$, where $\mathbf{y}_{\mathbf{i}}=$ $\left(y_{i 1}, y_{i 2}\right)$ is the pair of the last records observed on $i$ for trait $k(k=1,2)$ and $\delta$ is a vector of indicator variables denoting censored (0) or observed (1) record tagging of each of the $N$ observations for trait $k$. For a censored record, it is only known that the true value, $\eta_{i k}$, is larger than at the time of censoring, $C_{i k}$; otherwise, the true value is equal to the observed value [i.e., for trait $k$, $\left.y_{i k}=\min \left(\eta_{i k}, C_{i k}\right)\right]$. The setting was as in Carriquiry et al. (1987), but here, data augmentation (Sorensen et al., 1998; Guo et al., 2001) was used to generate latent data for censored observations for trait $k(k=1,2)$ whenever applicable: $\boldsymbol{\eta}_{\mathbf{c k}}=\left\{\eta_{i k}: \delta_{i k}=0\right\}$. Let $\mathbf{W}=\left(\boldsymbol{\eta}_{1}, \boldsymbol{\eta}_{2}\right)$ be the complete data vector of observed and augmented values for traits 1 and 2 , such that the sampling model is

$$
\mathbf{W} \mid \boldsymbol{\beta}, \mathbf{h}, \mathbf{p}, \mathbf{a}, \mathbf{R} \sim N\left(\mathbf{X} \boldsymbol{\beta}+\mathbf{Z}_{\mathbf{h}} \mathbf{h}+\mathbf{Z}_{\mathbf{p}} \mathbf{p}+\mathbf{Z}_{\mathbf{a}} \mathbf{a}, \mathbf{R} \otimes \mathbf{I}\right.
$$

where

$$
\mathbf{R}=\left[\begin{array}{cc}
\sigma_{e 1}^{2} & \sigma_{e 12} \\
\sigma_{e 12} & \sigma_{e 2}^{2}
\end{array}\right]
$$

is the residual covariance matrix between the 2 traits, and $\mathbf{I}$ is an identity matrix of an order equal to the number of records in the data set. The systematic effects $(\boldsymbol{\beta})$ in the preceding model were a regression on DFS 
as a covariate (only for INS); the effect of lactation age at calving (16 levels); the effect of calendar month of calving (12 levels); and the effect of year-season of calving (29 levels). Other effects in the model were $\mathbf{h}=$ herd (569 levels); $\mathbf{p}=$ permanent environmental effect of the cow (41,515 levels); and $\mathbf{a}=$ additive genetic effect of animal (85,974 levels). Furthermore, $\mathbf{X}, \mathbf{Z}_{\mathbf{h}}, \mathbf{Z}_{\mathbf{p}}$, and $\mathbf{Z}_{\mathbf{a}}$ were the corresponding incidence matrices of systematic effects of herd, permanent environmental effects, and additive genetic effects, respectively.

The following prior distributions were assumed:

$$
\begin{gathered}
p(\boldsymbol{\beta}): \text { improper uniform, } \\
\mathbf{h} \mid \mathbf{H} \sim N(\mathbf{0}, \mathbf{H} \otimes \mathbf{I}), \\
\mathbf{p} \mid \mathbf{P} \sim N(\mathbf{0 ,}, \mathbf{P} \otimes \mathbf{I}), \\
\mathbf{a} \mid \mathbf{G} \sim N(\mathbf{0}, \mathbf{G} \otimes \mathbf{A}),
\end{gathered}
$$

where

$$
\begin{aligned}
& \mathbf{H}=\left[\begin{array}{cc}
\sigma_{h 1}^{2} & \sigma_{h 12} \\
\sigma_{h 12} & \sigma_{h 2}^{2}
\end{array}\right], \\
& \mathbf{P}=\left[\begin{array}{cc}
\sigma_{p 1}^{2} & \sigma_{p 12} \\
\sigma_{p 12} & \sigma_{p 2}^{2}
\end{array}\right],
\end{aligned}
$$

and

$$
\mathbf{G}=\left[\begin{array}{cc}
\sigma_{a 1}^{2} & \sigma_{a 12} \\
\sigma_{a 12} & \sigma_{a 2}^{2}
\end{array}\right]
$$

are the $2 \times 2$ (co)variance matrices of herd, permanent environmental, and additive genetic effects, respectively, for the 2 traits, and $\mathbf{A}$ is the additive relationship matrix. The herd, permanent environmental, and additive genetic effects were assumed to be mutually independent, a priori. Independent inverse Wishart prior distributions were assigned to matrices $\mathbf{H}, \mathbf{P}, \mathbf{G}$, and $\mathbf{R}$.

Assuming that, conditional on model parameters $\boldsymbol{\theta}=$ $(\boldsymbol{\beta}, \mathbf{h}, \mathbf{p}, \mathbf{a}, \mathbf{H}, \mathbf{P}, \mathbf{G}, \mathbf{R})$, censoring is noninformative and independent, the augmented posterior distribution is given by

$$
\begin{gathered}
p\left(\boldsymbol{\theta}, \boldsymbol{\eta}_{\mathbf{c k}} \mid \mathbf{y}, \boldsymbol{\delta}\right) \propto p\left(\mathbf{y}, \boldsymbol{\delta}, \boldsymbol{\eta}_{\mathbf{c k}} \mid \boldsymbol{\theta}\right) p(\mathbf{h} \mid \mathbf{H}) p(\mathbf{H}) \\
p(\mathbf{p} \mid \mathbf{P}) p(\mathbf{P}) p(\mathbf{a} \mid \mathbf{G}) p(\mathbf{G}) p(\mathbf{e} \mid \mathbf{R}) p(\mathbf{R}),
\end{gathered}
$$

where

$$
\begin{aligned}
& p\left(\mathbf{y}, \boldsymbol{\delta}, \boldsymbol{\eta}_{\mathbf{c k}} \mid \boldsymbol{\theta}\right) \propto \prod_{i=1}^{N}\left[\mathrm{I}\left(\eta_{i k}>y_{i k}\right)\right]^{1-\delta_{i k}|\mathbf{R}|^{-\frac{1}{2}}} \\
& \exp \left\{-\frac{1}{2}\left[W_{i}-\mathrm{E}\left(W_{i}\right)\right]^{\prime} \mathbf{R}^{-1}\left[W_{i}-\mathrm{E}\left(W_{i}\right)\right]\right\} .
\end{aligned}
$$

Adopting a threshold model for INS (Gianola, 1982; Gianola and Foulley, 1983) and regarding the unobserved liabilities $\left(\boldsymbol{\lambda}=\boldsymbol{\eta}_{\mathbf{c k}}\right)$ of INS as a censored normal trait, the augmented posterior distribution follows the specification described above. Thus, if INS is observed, the liability $\eta_{i}$ corresponds to that for the appropriate category $j$ of INS, given the parameters. Otherwise, the censoring point $C_{i}$ was the value of the threshold $\left(T_{j}\right)$ corresponding to the category of the last, presumably unsuccessful, insemination observed (González-Recio et al., 2005), $J=1,2,3,4$, or $\geq 4$ indexes the categories to which an observation belongs, and $\mathbf{T}=\left[T_{1}, \ldots, T_{4}\right]^{\prime}$ is the $4 \times 1$ vector of unknown thresholds. Also, the first threshold $T_{1}$ was set to zero, because this parameter cannot be identified in a probit analysis. Furthermore, the remaining 3 thresholds were sampled by adapting an efficient method proposed by Albert and Chib (1997), as described by González-Recio et al. (2005). In this censored linear-threshold model, the prior distribution of the residual variance of the Gaussian trait $\left(\sigma_{e_{1}}^{2}\right)$ was scaled inverted $\chi^{2}$, whereas that of the residual covariance between the linear and the threshold trait was uniform on $\left(-\sqrt{\sigma_{e_{1}}^{2}}, \sqrt{\sigma_{e_{1}}^{2}}\right)$. Draws from the posterior distribution of heritability were formed as

$$
\mathbf{h}^{2}=\frac{\sigma_{a}^{2}}{\sigma_{a}^{2}+\sigma_{e}^{2}+\sigma_{p}^{2}} .
$$

Posterior distributions of the parameters of interest were estimated using a Gibbs-Metropolis algorithm (Gelfand and Smith, 1990; Sorensen et al., 1995; Sorensen and Gianola, 2002). The analyses were based on a single chain of 100,000 iterations, with the first 10,000 samples discarded as burn-in.

\section{Incorporating Fertility into the Selection Index}

Different selection schemes were compared based on selection index theory with discounted economic weights of traits in the breeding objective (Hazel, 1943; Hazel et al., 1994). Actual milk, fat, and protein yields were included in the aggregate genotype, as were 2 fertility traits related to the initiation of ovarian activity and pregnancy rate (DFS and liability to INS, respectively). Economic values reported in a recent study by González-Recio et al. (2004) were used $(\$ 0.13, \$ 1.02$, 
Table 1. Mean, standard deviation, and percentage of censored records for 305-d adjusted milk (MY305); actual yield for milk (MY), fat, and protein per lactation (kg); days to first service (DFS); days open (DO); and number of insemination to conception (INS)

\begin{tabular}{llccc}
\hline Trait & $\begin{array}{l}\text { Number } \\
\text { of records }\end{array}$ & Mean & SD & $\begin{array}{l}\text { Censored } \\
\text { records, \% }\end{array}$ \\
\hline MY305 & 71,217 & 8,805 & 1,869 & $0^{1}$ \\
MY & 71,217 & 9,582 & 2,845 & $0^{1}$ \\
Protein & 71,217 & 355 & 112 & $0^{1}$ \\
Fat & 71,217 & 305 & 93 & $0^{1}$ \\
DFS & 71,217 & 84 & 32 & $0^{2}$ \\
DO & 71,217 & 131 & 69 & 30 \\
INS & 71,217 & 1.90 & 1.06 & 36 \\
\hline
\end{tabular}

${ }^{1}$ Only complete production records were included in the analyses. ${ }^{2}$ Only lactations with first insemination were included in the analyses.

$\$ 4.04,-\$ 4.90$, and $-\$ 67.32$ per cow per year, for kilograms of MY, fat, protein, calving interval, and INS, respectively). The economic value for calving interval was used for DFS, because increasing DFS by $1 \mathrm{~d}$ had the same economic impact as increasing the calving interval by $1 \mathrm{~d}$. Hence, the aggregate genotype $(H)$ was

$$
\begin{gathered}
H=e v_{1} \cdot \text { milk }+e v_{2} \cdot \text { fat }+e v_{3} \cdot \text { protein } \\
+e v_{4} \cdot \mathrm{INS}+e v_{5} \cdot \mathrm{DFS}
\end{gathered}
$$

where INS is liability for the number of inseminations to conception and $e v_{1}, e v_{2}, e v_{3}, e v_{4}$, and $e v_{5}$ are the respective economic values given above.

Four indices were studied: Actual milk, fat, and protein yields were always considered, along with various combinations of fertility traits (specifically, liability to INS, DO, INS + DO, INS + DFS). Correlated genetic response, per generation interval, was assessed, assuming that selection intensity was equal to one.

\section{RESULTS AND DISCUSSION}

A summary of data is given in Table 1. Average MY305 was $8,805 \mathrm{~kg}$, whereas average MY was 9,582 $\mathrm{kg}$, with $3.7 \%$ fat and $3.2 \%$ protein. Mean DFS was 84 $\mathrm{d}$ postpartum, and mean DO and INS for uncensored records were $126 \mathrm{~d}$ and 1.7 inseminations, respectively. The data set contained 30 and 36\% right-censored records for DO and INS, respectively. Production traits and DFS had no censored records, because only complete lactations with a first insemination event were included.

\section{Genetic Parameters}

Heritability estimates are shown in Table 2. Heritability estimates for MY305 and fat yield were 0.25 and 0.18 , respectively, whereas MY and protein had herita-
Table 2. Heritability ${ }^{1}$ estimates $\left(\mathrm{h}^{2}\right)$ and posterior residual, herd, and permanent environmental variance ratios (relative to total variance) for production and fertility traits $^{2}$

\begin{tabular}{lllll}
\hline Trait & $\mathrm{h}^{2}$ & $\begin{array}{l}\text { Residual } \\
\text { ratio }\end{array}$ & $\begin{array}{l}\text { Herd } \\
\text { ratio }\end{array}$ & $\begin{array}{l}\text { Permanent } \\
\text { environmental } \\
\text { ratio }\end{array}$ \\
\hline MY305 & 0.25 & 0.37 & 0.38 & 0.10 \\
MY & 0.19 & 0.54 & 0.20 & 0.11 \\
Protein & 0.19 & 0.54 & 0.22 & 0.11 \\
Fat & 0.18 & 0.54 & 0.20 & 0.11 \\
DFS & 0.05 & 0.74 & 0.16 & 0.05 \\
DO & 0.05 & 0.88 & 0.04 & 0.05 \\
INS & 0.04 & 0.89 & 0.05 & 0.03 \\
\hline
\end{tabular}

${ }^{1}$ Heritability $=\sigma_{a}^{2} /\left(\sigma_{a}^{2}+\sigma_{e}^{2}+\sigma_{p}^{2}\right)$.

${ }^{2}$ Production traits: 305-d adjusted milk yield (MY305), and total yield per lactation for milk (MY), fat, and protein. Fertility traits: days to first service (DFS), days open (DO), and number of inseminations to conception (INS). Posterior standard deviations were $<0.01$.

bility estimates of 0.19 . Heritability estimates of actual production were generally lower than estimates for MY305, which typically range from 0.20 to 0.33 (Kadarmideen et al., 2003; Wall et al., 2003; Dechow et al., 2004).

Estimated heritability of INS on the liability scale (0.04) was similar to values in other reports (Veerkamp et al., 2001; Kadarmideen et al., 2003; González-Recio et al., 2005). Chang et al. (2006) obtained heritability estimates of 0.04 for both INS, on the liability scale, and DO in a Norwegian Red dairy population, after fitting a censored threshold-linear sire model. Van Arendonk et al. (1989) reported heritability estimates ranging from 0.01 to 0.03 using a linear sire model and computing DO from the subsequent calving date. Dematawewa and Berger (1998) found a heritability estimate of 0.04 , based on limiting DO to a maximum of $305 \mathrm{~d}$, using a linear animal model. Van Raden et al. (2004) reported an estimate of 0.037 for uncensored DO in US Holsteins. The heritability of DFS (0.05) was similar to that reported by González-Recio and Alenda (2005) and slightly higher than the estimate (0.03) of Andersen-Ranberg et al. (2005). The posterior standard deviations of heritabilities were approximately 0.01 .

Residual, herd, and permanent environmental variances as a fraction (ratio) of the total variance are also shown in Table 2. Fertility traits had lower herd $(0.04$ to 0.16$)$ and permanent environmental effect $(0.03$ to $0.05)$ ratios. Herd and permanent environmental effect ratios ranged from 0.20 to 0.38 , and from 0.10 to 0.11 , respectively, for production traits.

Fertility traits were genetically positively correlated (Table 3), with correlations ranging from 0.41 between INS and DFS to 0.87 between DO and DFS. Days open and INS had an estimated genetic correlation of 0.71 . These results suggest that cows that show heat later 
Table 3. Posterior means and standard deviations (in parentheses) of genetic correlations between production and fertility traits ${ }^{1}$

\begin{tabular}{llllll}
\hline Trait & Fat & MY & DFS & DO & INS \\
\hline MY305 & - & $0.96_{(0.02)}$ & $0.47_{(0.04)}$ & $0.63_{(0.09)}$ & $0.23_{(0.06)}$ \\
Protein & $0.82_{(0.03)}$ & $0.89_{(0.04)}$ & $0.58_{(0.04)}$ & $0.76_{(0.04)}$ & $0.22_{(0.05)}$ \\
Fat & & $0.71_{(0.04)}$ & $0.53_{(0.05)}$ & $0.75_{(0.06)}$ & $0.21_{(0.06)}$ \\
MY & & & $0.59_{(0.04)}$ & $0.74_{(0.04)}$ & $0.16_{(0.05)}$ \\
DFS & & & & $0.87_{(0.03)}$ & $0.41_{(0.07)}$ \\
DO & & & & & $0.71_{(0.05)}$ \\
\hline
\end{tabular}

${ }^{1}$ Production traits: $305-\mathrm{d}$ adjusted milk yield (MY305), and total yield per lactation for milk (MY), fat, and protein. Fertility traits: days to first service (DFS), days open (DO), and number of inseminations to conception (INS).

in lactation are genetically less fertile and require more inseminations to achieve pregnancy, resulting in extended DO. In general, strong genetic correlations among fertility traits have also been reported in other studies (Veerkamp et al., 2001; Kadarmideen et al., 2003). Chang et al. (2006) estimated a genetic correlation of 0.77 between DO and INS using similar methodology in the Norwegian Red dairy population. Genetic correlation estimates between production and fertility traits in this study agree with the well-known antagonism between these traits (Dechow et al., 2001; Veerkamp et al., 2001; Brotherstone et al., 2002). Cows with higher yields tend to have poorer reproductive performance. Days open had the highest genetic correlation with production traits (0.63 to 0.76$)$, whereas genetic correlations between INS and yields ranged from 0.16 to 0.23 (Table 3). Days open seemed to be more strongly related to production than was INS. Management decisions to delay first insemination in high-yielding cows could be one reason for longer DO (Wall et al., 2003). Likewise, increased DO might not be economically adverse if an adequate production level can be sustained. Therefore, INS seems to be a preferable trait for evaluating female fertility, because it is much less correlated with production and because it measures female fertility directly. Other studies have also found larger genetic correlations between DO and production than between INS and milk output (Brotherstone et al., 2002; Kadarmideen et al., 2003; Wall et al., 2003).

As expected, a large positive correlation (0.96) was found between MY and MY305 (Table 3). However, MY305 was genetically less correlated with DFS and DO (0.47 and 0.63 , respectively) than was MY ( 0.59 and 0.74 , respectively). If dairy farmers attempt to reach a 365 -d calving interval by inseminating cows early in lactation, MY and MY305 will coincide. However, González-Recio (unpublished data) estimated a genetic correlation between MY305 and post-305-d milk yield (MY - MY305) of 0.75, suggesting that milk produced after 305 DIM might be more heavily influenced by management decisions and fertility.

\section{Expected Genetic Gain}

Results suggest that it is unlikely to improve fertility by selecting for production and profitability (Table 4), but genetic degradation of fertility could be slowed down by including fertility in the total merit index. Deterioration of fertility was similar regardless of the selection index considered. However, expected economic progress ranged between $\$ 185$ and $\$ 272$ per cow per generation. These results suggest that maximization of profitability is achieved with a slight deterioration of reproductive ability, because added costs are compensated for by increased income from milk sales. The largest genetic progress for profit $(+\$ 272)$ was obtained when INS was the only fertility trait in the selection index, whereas including DO as the only fertility trait or including it jointly with DFS led to the lowest progress in profit. Extending the voluntary waiting period for high-yielding cows to obtain longer lactations might improve profitability; therefore, longer DO may not be economically adverse, and INS is preferable as a selection criterion for female fertility. Because DO can be calculated from dates in the milk recording scheme and because DFS is another widely used trait, an optimal solution could be to include a subpopulation in a reproductive recording scheme and evaluate DO and DFS simultaneously using missing values for DFS. However, in such an index, coefficients for DO would be positive, because of the high genetic correlation between DO and production, and this may be hard to interpret. Higher weights for fertility in the selection indices could improve fertility, but profitability would be reduced because genetic progress for production traits would be lower.

It must be pointed out that some current market rules and conditions in the dairy industry are not considered in the bioeconomic models such as opportunity costs or farmer's quality of life. Introducing these aspects into the profit function could change the results found. In addition, expected genetic gain was calculated by considering a hypothetical situation, and actual responses might vary, considering the low reliabilities for fertility traits in first lactations.

The global profitability of cows includes production, fertility, health, and efficiency. In this study, we considered only the deterioration of fertility as milk yield increases. Health problems, such as mastitis, may also appear when production increases (Philipsson and Lindhé, 2003), thereby decreasing profitability. Therefore, future studies should consider such circumstances. Other functional traits should be studied and included in the total merit indices to improve production and avoid deterioration of functionality, thereby increasing profitability in future generations. 
Table 4. Index weights and genetic gain in US dollars and on breeding objective traits ${ }^{1}$ for each selection index

\begin{tabular}{|c|c|c|c|c|c|c|c|}
\hline Index & Index weights $(\%)$ & \multicolumn{6}{|c|}{ Expected genetic gain ${ }^{2}$} \\
\hline $\mathrm{I}_{1}$ & $39 \cdot \mathrm{MY}+12 \cdot \mathrm{FAT}+42 \cdot \mathrm{PROT}-7 \cdot \mathrm{INS}$ & +982 & +34 & +32 & +4.11 & +0.03 & +272 \\
\hline $\mathrm{I}_{3}$ & $34 \cdot \mathrm{MY}+14 \cdot \mathrm{FAT}+35 \cdot \mathrm{PROT}-16 \cdot \mathrm{DO}$ & +734 & +26 & +24 & +2.57 & +0.01 & +206 \\
\hline $\mathrm{I}_{4}$ & $31 \cdot \mathrm{MY}+11 \cdot \mathrm{FAT}+21 \cdot \mathrm{PROT}+1 \cdot \mathrm{DO}-36 \cdot \mathrm{DFS}$ & +679 & +24 & +22 & +2.94 & +0.03 & +185 \\
\hline
\end{tabular}

${ }^{1}$ Breeding objective traits: total yield for milk (MY), fat, and protein (PROT); days to first service (DFS); and number of inseminations per service period (INS).

${ }^{2}$ Genetic gain calculated assuming selection intensity of 1.0 and the same generation interval for every trait.

\section{CONCLUSIONS}

The censored threshold-linear and censored linearlinear models were used successfully to estimate (co)variance components among production and fertility traits. Number of inseminations to conception measures female fertility directly and indicates the probability of conception when a cow is given the opportunity to get pregnant. Furthermore, the inclusion of INS in a selection index would achieve higher expected genetic gain in profit, increasing genetic progress for milk yield and slowing the rate of genetic degradation for female fertility.

The relationship between production and fertility seems to depend on whether MY or MY305 is considered. Because extending the lactation length may be profitable in some cases, further research should be carried out on the merit of choosing MY or MY305 with regard to profit, persistency, and fertility.

\section{ACKNOWLEDGMENTS}

Support by the Wisconsin Agriculture Experiment Station, through grants NRICGP/USDA 2003-3520512833 and NSF DEB-0089742, and by the Spanish Research Project PROFIT 010000-2003-132 (Centro para el Desarrollo Tecnológico Industrial) is acknowledged. The authors thank the Basque Country and Navarre Holstein Associations for providing the data.

\section{REFERENCES}

Andersen-Ranberg, I. M., G. Klemetsdal, B. Heringstad, and T. Steine. 2005. Heritabilities, genetic correlations, and genetic change for female fertility and protein yield in Norwegian Dairy Cattle. J. Dairy Sci. 88:348-355.

Albert, J. H., and S. Chib. 1997. Bayesian Methods for Cumulative, Sequential and Two-Step Ordinal Data Regression Models. Technical Report. Department of Mathematics and Statistics, Bowling Green State University, Bowling Green, $\mathrm{OH}$.

Boichard, D. 1990. Estimation of the economic value of conception rate in dairy cattle. Livest. Prod. Sci. 24:187-204.

Brotherstone, S., G. Banos, and M. P. Coffey. 2002. Evaluation of yield traits for the development of a UK fertility index for dairy cattle. 7th World Congress on Genetics Applied to Livestock Production, Montpellier, France. Communication 01-28.
Carriquiry, A. L., D. Gianola, and R. L. Fernando. 1987. Mixed model analysis of a censored normal distribution with reference to animal breeding. Biometrics 43:929-939.

Chang, Y. M., I. M. Andersen-Ranberg, B. Heringstad, D. Gianola, and G. Klemetsdal. 2006. Bivariate analysis of number of services to conception and days open in Norwegian Red using a censored threshold-linear model. J. Dairy Sci. 89:772-778.

Dechow, C. D., G. W. Rogers, and J. S. Clay. 2001. Heritabilities and correlations among body condition scores, production traits, and reproductive performance. J. Dairy Sci. 84:266-275.

Dechow, C. D., G. W. Rogers, L. Klei, T. J. Lawlor, and P. M. VanRaden. 2004. Body condition scores and dairy form evaluations as indicators of days open in US Holstein. J. Dairy Sci. 87:35343541.

Dematawewa, C. M. B., and P. J. Berger. 1998. Genetic and phenotypic parameters for 305-day yield, fertility, and survival in Holstein. J. Dairy Sci. 81:2700-2709.

Gelfand, A., and A. F. M. Smith. 1990. Sampling based approaches to calculating marginal densities. J. Anim. Stat. Assoc. 85:398-409.

Gianola, D. 1982. Theory and analysis of threshold characters. J. Anim. Sci. 54:1079-1096.

Gianola, D., and J. L. Foulley. 1983. Sire evaluation for ordered categorical data with a threshold model. Genet. Sel. Evol. 15:201-224.

González-Recio, O., and R. Alenda. 2005. Genetic parameters for female fertility traits and a fertility index in Spanish dairy cattle. J. Dairy Sci. 88:3282-3289.

González-Recio, O., Y. M. Chang, D. Gianola, and K. Weigel. 2006. Comparisons of models using different censoring scenarios for days open in Spanish Holstein cows. Anim. Sci. 82:233-239.

González-Recio, O., Y. M. Chang, D. Gianola, and K. Weigel. 2005. Number of inseminations to conception in Holstein cows using censored records and time-dependent covariates. J. Dairy Sci. 88:3655-3662.

González-Recio, O., M. A. Pérez-Cabal, and R. Alenda. 2004. Economic value of female fertility and its relationship with profit in Spanish dairy cattle. J. Dairy Sci. 87:3053-3061.

Guo, S. F., D. Gianola, R. Rekaya, and T. Short. 2001. Bayesian analysis of lifetime performance in Landrace sows using a linear mixed model with censoring. Livest. Prod. Sci. 72:243-252.

Hazel, L. N. 1943. The genetic basis for constructing selection indices. Genetics 28:476-490.

Hazel, L. N., G. E. Dickerson, and A. E. Freeman. 1994. The selection index-Then, now, and for the future. J. Dairy Sci. 77:3236-3251.

Kadarmideen, H. N., R. Thompson, M. P. Coffey, and M. A. Kossaibati. 2003. Genetic parameters and evaluations from single- and multiple-trait analysis of dairy cow fertility and milk production. Livest. Prod. Sci. 81:183-195.

Philipsson, J., and B. Lindhé. 2003. Experiences of including reproduction and health traits in Scandinavian dairy cattle breeding programmes. Livest. Prod. Sci. 83:99-112.

Sorensen, D., S. Andersen, D. Gianola, and I. Korsgaad. 1995. Bayesian inference in threshold model using Gibbs sampling. Genet. Sel. Evol. 27:229-249. 
Sorensen, D., and D. Gianola. 2002. Likelihood, Bayesian, and MCMC Methods in Quantitative Genetics. Springer-Verlag, New York, NY.

Sorensen, D. A., D. Gianola, and I. R. Korsgaard. 1998. Bayesian mixed effects model analysis of a censored normal distribution with animal breeding applications. Acta Agric. Scand. 48:222229.

Stott, A. W., R. F. Veerkamp, and T. R. Wassell. 1999. The economics of fertility in the dairy herd. Anim. Sci. 68:49-57.

Thaller, G. 1997. GIFT's in cattle. Workshop on fertility and reproduction: Genetics and breeding for fertility. Interbull Bull. 18:55-61.

Van Arendonk, J. A. M., R. Hovenier, and W. Deboer. 1989. Phenotypic and genetic association between fertility and production in dairy cows. Livest. Prod. Sci. 21:1-12.

Van Raden, P. M., A. H. Sanders, M. E. Tooker, R. H. Miller, H. D. Norman, M. T. Kuhn, and G. R. Wiggans. 2004. Development of a national genetic evaluation for cow fertility. J. Dairy Sci. 87:2285-2292.

Vargas, B., A. F. Groen, M. Herrero, and J. A. M. Van Arendonk. 2002. Economic values for production and functional traits in Holstein cattle of Costa Rica. Livest. Prod. Sci. 75:101-116.

Varona, L., I. Misztal, and J. K. Bertrand. 2001. Threshold-linear versus linear-linear analysis of birth weight and calving ease using an animal model: II. Comparison of models. J. Anim. Sci. 77:2003-2007.

Veerkamp, R. F., E. P. C. Koenen, and G. De Jong. 2001. Genetic correlations among body condition score, yield, and fertility in first-parity cows estimated by random regression models. J. Dairy Sci. 84:2327-2335.

Wall, E., S. Brotherstone, J. A. Woolliams, G. Banos, and M. P. Coffey. 2003. Genetic evaluation of fertility using direct and correlated traits. J. Dairy Sci. 86:4093-4102. 